\title{
Treatment of an osteoporotic vertebral compression fracture with the StaXx FX system resulting in intrathoracic wafers: a serious complication
}

\author{
L. W. van der Plaat $\cdot$ G. H. Bulstra \\ G. H. R. Albers · J. P. Eerenberg $\cdot$ H. M. van der Vis
}

Received: 16 June 2011/Revised: 14 October 2011/ Accepted: 15 October 2011 / Published online: 2 November 2011

(C) The Author(s) 2011. This article is published with open access at Springerlink.com

\begin{abstract}
Purpose To report a serious complication of the StaXx FX system used to stabilize an osteoporotic vertebral fracture.

Case report A 76-year-old woman presented with a painful vertebral fracture. Treatment by means of a PEEK wafer kyphoplasty was complicated by malposition of the wafers. The patient recovered fully after removal of the wafers by means of a thoracotomy.

Conclusions New treatment modalities have their own pitfalls and possible complications, as demonstrated in this case report. Caution regarding implementation of new treatment modalities should be practiced.
\end{abstract}

Keywords Spine - Osteoporosis · Fracture ·

Kyphoplasty $\cdot$ StaXx FX

L. W. van der Plaat $(\bowtie)$

Department of Orthopaedic Surgery, Academic Medical Center,

Postbus 22660, 1100 DD Amsterdam, The Netherlands

e-mail: Lplaat@hotmail.com

\section{G. H. Bulstra}

Department of Orthopaedic Surgery, Sint Lucas Andreas

Hospital, Amsterdam, The Netherlands

G. H. R. Albers - H. M. van der Vis

AVE Orthopaedic Clinics, Huizen, The Netherlands

J. P. Eerenberg

Department of General Surgery, Ter Gooi Hospital, Hilversum,

The Netherlands

\section{Introduction}

The impact of osteoporotic vertebral compression fractures (VCF) on mortality [1] and quality of life [2] is increasingly acknowledged. Despite successful conservative treatment of the majority of patients [3], 37\% of patients referred for an X-ray of the thoracic or lumbar spine by their general practitioner still experience pain after six months [4]. Vertebroplasty (VP), originally developed for treatment of vertebral angiomas [5] and kyphoplasty (KP) are now commonly accepted treatment options for VCFs.

Potentially serious complications (cement leakage leading to pulmonary emboli or neurological deficit) of VP and KP have been reported [6-8]. An alternative KP procedure uses sequentially inserted $1-\mathrm{mm}$ thick polyetheretherketone (PEEK) wafers for controlled and vertically oriented kyphosis correction (StaXx FX system, Spine Wave, Inc, Shelton, USA). The theoretical advantages over other VP and KP procedures are retained fracture reduction, less cement leakage and restoration of the loadbearing properties of the intervertebral disc [9].

Complications can occur with all surgical procedures, but especially when they are serious and occur while using a new device lacking clinical results publication is warranted. We present a case report of a PEEK wafer KP resulting in anterolateral perforation of the vertebral body, necessitating a thoracotomy.

\section{Case report}

A 76-year-old, vital woman with a history of osteoporosis and a transient ischemic attack visited our outpatient clinic, with high back pain, interfering with daily activities. The pain occurred spontaneously 2 months earlier, and did not 


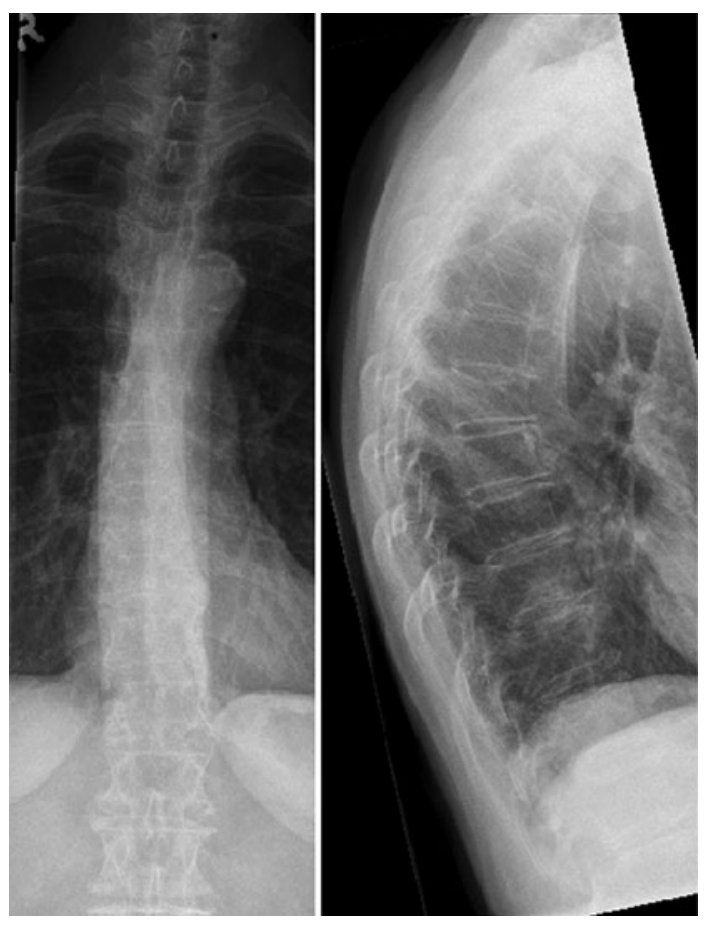

Fig. 1 Thoracic spine X-rays showing the T7 fracture

improve with acetaminophen and activity modification. On physical examination $(59 \mathrm{~kg}, 1.58 \mathrm{~m})$, compression pain over the spinal column and painful palpation of the spinous processes T6 and T7 was noted. Thoracic spine X-rays revealed an impression deformity of $\mathrm{T} 7$, with $15 \%$ anterior height loss (Fig. 1), AO type A1.2. MRI showed oedema, sign of a recent/active fracture. Due to failure of conservative therapy, the fracture was stabilized using a PEEK wafer KP.

After general anaesthesia and antibiotic prophylaxis (1,000 mg cefamandole) and prone positioning, a K-wire was inserted from a left extrapedicular entry position using fluoroscopy. After measuring the length, the sizer was inserted followed by gently tapping the wafer gun into the vertebra. The device penetrated the anterolateral cortex, and was withdrawn to the correct depth. During insertion of the first few wafers anterolateral protrusion was observed on fluoroscopy. Despite this observation, more wafers were introduced and these seemed to be positioned correctly. However, subsequent wafers again seemed to protrude (Fig. 2), therefore the procedure was terminated. Stabilization of the wafers by adding bone cement was omitted because of potential cement leakage into the thoracic cavity. The patient remained stable, and a direct postoperative X-ray revealed no pneumothorax, thus watchful waiting was performed after consulting a thoracic surgeon.

The thoracic spine X-ray performed the following day confirmed malposition of the wafers. The patient remained in good general condition, and was discharged from the hospital. The patient was prescribed acetaminophen with codeine 500/20 mg 4 times 2 daily and tramadol $50 \mathrm{mg} 3$ times 1 daily (VAS 4).

One week later she visited the emergency department with unbearable high back and right-sided thoracic pain (VAS 10), without dyspnoea. Tramadol had been replaced with Naproxen because of hallucinations. On physical examination, she was hemodynamically stable, without neurological deficit, but axial compression of the spinal column was painful. There were no signs of infection. Progressive displacement of one wafer was noted on the thoracic spine X-ray (Fig. 3). The anterior vertebral height loss had increased to $32 \%$, probably due to the weakening of the vertebral body by the previous surgery. A CT-scan revealed protrusion of the wafers, in close proximity to the right pulmonary artery and stem bronchus, with fluid in the right pleural cavity (Fig. 4). After consultation with the
Fig. 2 Intra-operative fluoroscopy of malpositioned wafers
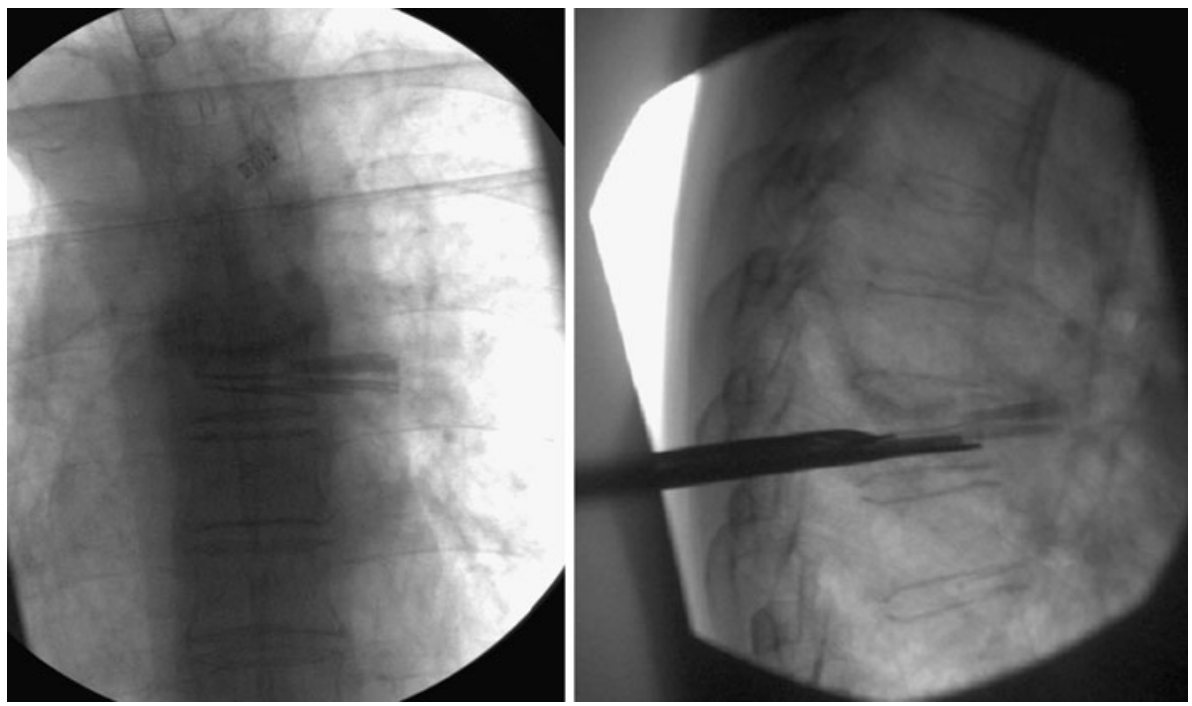

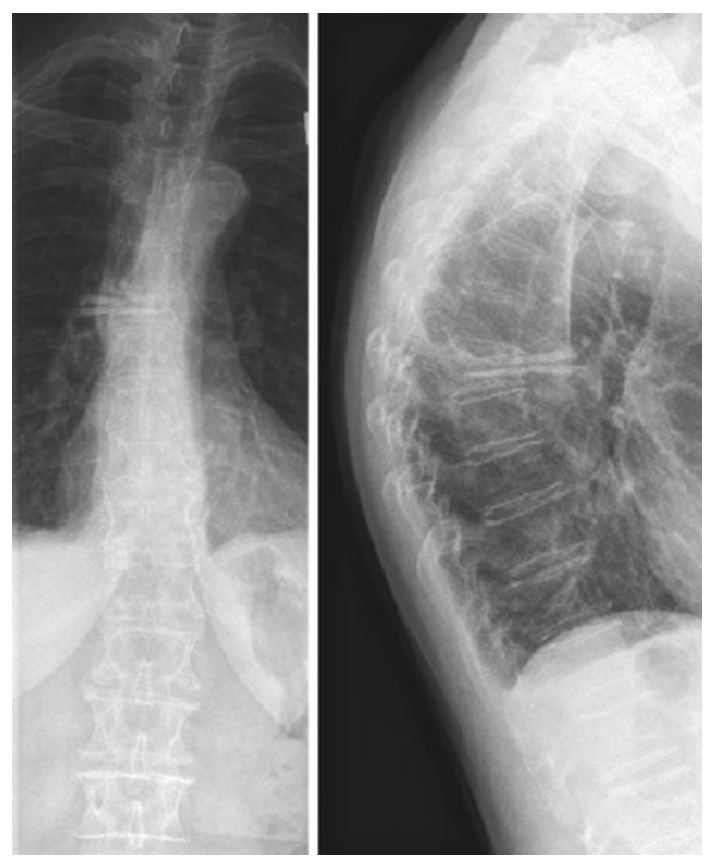

Fig. 3 X-ray of the thoracic spine showing progressive malposition of one of the wafers

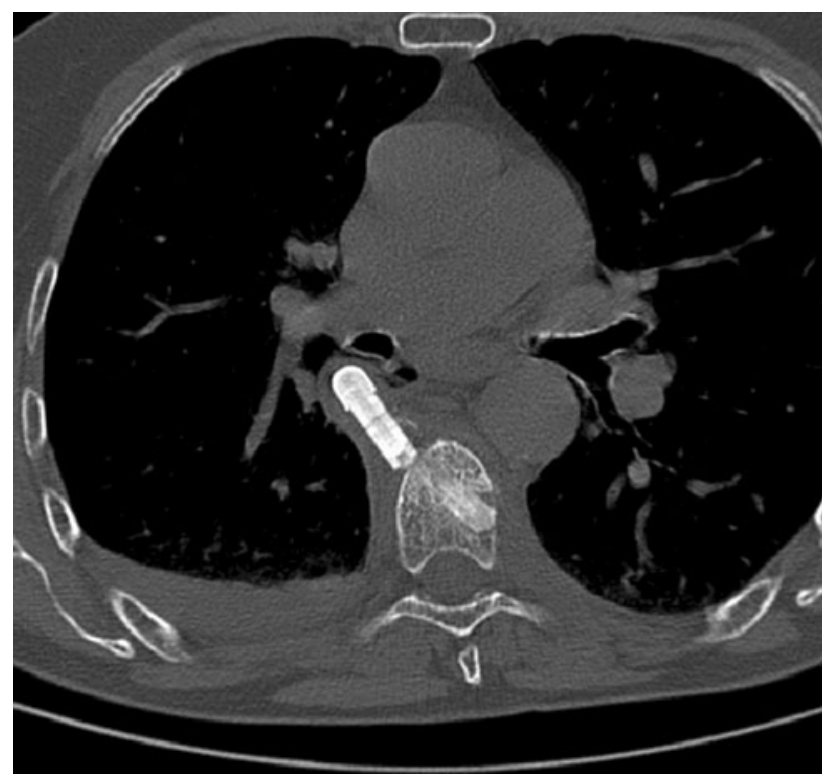

Fig. 4 CT-scan transversal view showing the malpositioned wafers with close relation to the right pulmonary artery and right stem bronchus

thoracic surgeon, we decided to remove the wafers, and use an alternative method of stabilisation.

Following general anaesthesia and antibiotic prophylaxis (1,000 $\mathrm{mg}$ cefamandole) and left-sided positioning a right posterolateral thoracotomy was performed. By blocking ventilation the right lung collapsed. The wafers penetrated the parietal and visceral pleura (Fig. 5). The vagal nerve was

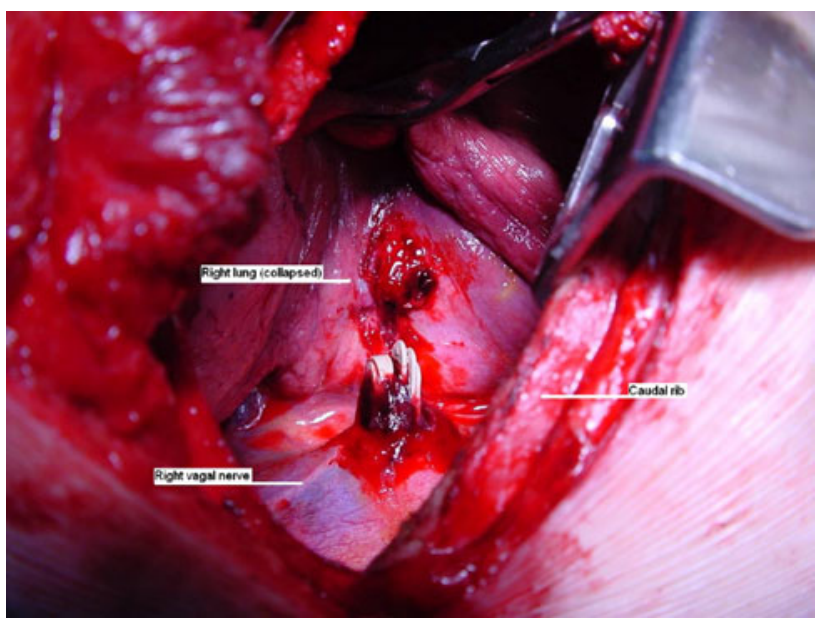

Fig. 5 Intra-operative photo showing the protruding wafers

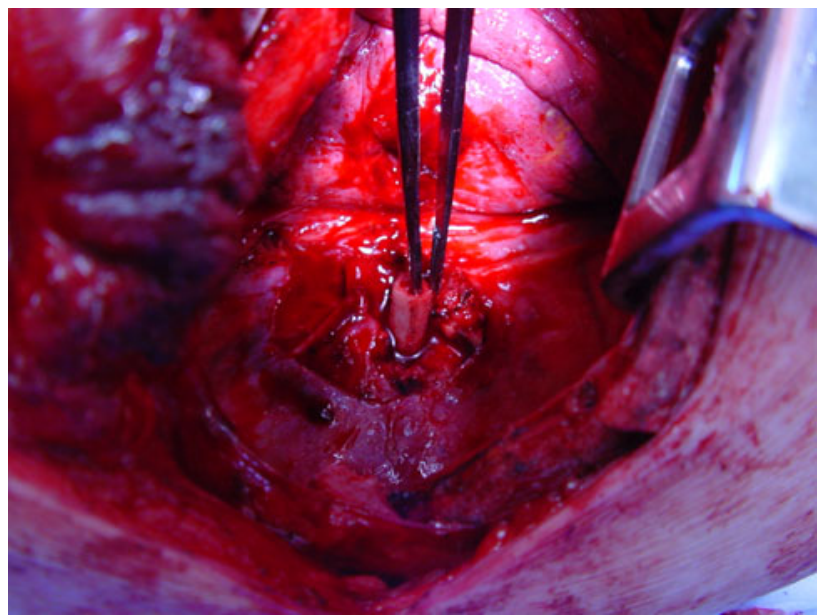

Fig. 6 Intra-operative photo showing the resected piece of rib before insertion in the vertebral body

stretched around the wafers, but intact. After removal of the wafers, the residual cavity in the vertebral body was probed and deemed circumferentially intact. It was filled with a resected piece of the sixth rib (Fig. 6). An intrathoracic suction drain and a subpleural analgesic catheter were inserted. The right lung was inflated and the thoracotomy closed with thick double stranded sutures followed by routine wound closure.

Postoperatively she went to the ICU, and was transferred to the orthopaedic ward the next day after a thoracic X-ray revealed absent residual pneumothorax. Within 2 days the excruciating pain subsided, although analgesics were required for thoracotomy wound pain. X-rays and a CT-scan showed proper positioning of the rib-graft in the vertebra (Fig. 7). Three days postoperation, atrial fibrillation developed and was successfully treated with digoxin. She was discharged in good health after 19 days with a 3 -point extension spinal orthosis for 6 weeks. 
Fig. 7 Postoperative CT-scan of the thoracic spine showing the position of the rib graft within the vertebral body

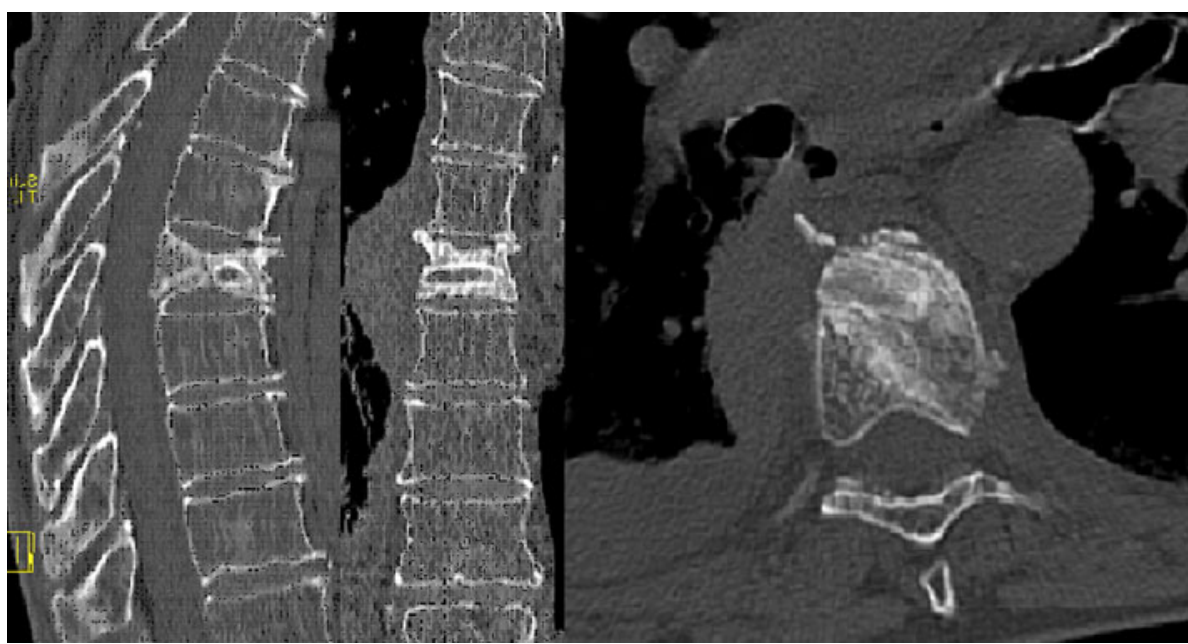

\section{Discussion}

We present a serious complication of a PEEK wafer KP procedure in an osteoporotic VCF. Fortunately, the patient recovered extremely well. In addition to investigating characteristics of bone substitutes to decrease complications of VP and KP [10-13], alternatives and modifications of VP and KP are currently emerging. These include lordoplasty [14], vesselplasty [15], vertebral body stenting [16], mesh-allograft-stenting [17], among others [18], as well as the StaXx FX system. In experimentally created VCFs, partial endplate reduction and kyphosis correction could be achieved with the StaXx FX system, with intervertebral disk pressure corrected to $86 \%$ of normal [9]. In addition, in 26 VCFs treated with the device, a significant decrease in visual analogue scale (VAS) pain score was observed after 8 months of follow-up [19]. No clinical reports comparing these alternatives of $\mathrm{VP}$ and $\mathrm{KP}$ to regular VP or KP or conservative treatment are available. Surgical treatment of VCFs unresponsive to conservative therapy (with VP or KP) remains controversial [20-29]. In a subgroup of patients, VP appears to be superior to conservative treatment [30]. Unfortunately, at the moment it is not possible to identify these patients shortly after they sustain a VCF.

Regarding the complication described in this article, we think there are two possible explanations:

1. Perforation of the vertebral cortex with the wafer gun, creating a hole through which the wafers could protrude (faulty surgical technique). Perhaps at this moment switching to another method of stabilisation (for instance posterior instrumentation) would have been preferred. A more gradual increase in diameter of the wafer gun possibly lowers resistance during insertion, which might reduce occurrence of this complication.
2. A design flaw in the wafer gun allowing the wafers to progress beyond its anterior rim. Perhaps a higher anterior rim or different wafer shape would prevent this.

Incidence and prevalence of osteoporotic VCFs will increase. Heightened awareness of their impact on quality of life and mortality is changing our view of these fractures. Patients today are better informed and more assertive, in demanding (surgical) treatment. Nevertheless, we need to remain critical of new treatment modalities while their (long-term) results and complications are unknown. We feel it is important to describe complications occurring while using (new) surgical systems.

Acknowledgments We would like to thank Mr. S. Westerbos, MD for his valuable contribution to this article. No funds or benefits have been or will be received for this manuscript.

Conflict of interest None of the authors has any potential conflict of interest.

Open Access This article is distributed under the terms of the Creative Commons Attribution Noncommercial License which permits any noncommercial use, distribution, and reproduction in any medium, provided the original author(s) and source are credited.

\section{References}

1. Ioannidis G, Papaioannou A, Hopman WM, Akhtar-Danesh N, Anastassiades T, Pickard L, Kennedy CC, Prior JC, Olszynski WP, Davison KS, Goltzman D, Thabane L, Gafni A, Papadimitropoulos EA, Brown JP, Josse RG, Hanley DA, Adachi JD (2009) Relation between fractures and mortality: results from the Canadian multicentre osteoporosis study. CMAJ 181(5):265-271

2. Papaioannou A, Kennedy CC, Ioannidis G, Sawka A, Hopman WM, Pickard L, Brown JP, Josse RG, Kaiser S, Anastassiades T, Goltzman D, Papadimitropoulos M, Tenenhouse A, Prior JC, Olszynski WP, Adachi JD (2009) The impact of incident fractures on health-related quality of life: 5 years of data from the 
Canadian multicentre osteoporosis study. Osteoporos Int 20(5):703-714

3. Papaioannou A, Watts NB, Kendler DL, Yuen CK, Adachi JD, Ferko N (2002) Diagnosis and management of vertebral fractures in elderly adults. Am J Med 113(3):220-228

4. Klazen CA, Verhaar HJ, Lohle PN, Lampmann LE, Juttmann JR, Schoemaker MC, van Everdingen KJ, Muller AF, Mali WP, de Vries J (2010) Clinical course of pain in acute osteoporotic vertebral compression fractures. $\mathrm{J}$ Vasc Interv Radiol 21(9):1405-1409

5. Grados F, Depriester C, Cayrolle G, Hardy N, Deramond H, Fardellone P (2000) Long-term observations of vertebral osteoporotic fractures treated by percutaneous vertebroplasty. Rheumatology (Oxford) 39(12):1410-1414

6. Teng MM, Cheng H, Ho DM, Chang CY (2006) Intraspinal leakage of bone cement after vertebroplasty: a report of 3 cases. Am J Neuroradiol 27(1):224-229

7. Freitag M, Gottschalk A, Schuster M, Wenk W, Wiesner L, Standl TG (2006) Pulmonary embolism caused by polymethylmethacrylate during percutaneous vertebroplasty in orthopaedic surgery. Acta Anaesthesiol Scand 50(2):248-251

8. Monticelli F, Meyer HJ, Tutsch-Bauer E (2005) Fatal pulmonary cement embolism following percutaneous vertebroplasty (PVP). Forensic Sci Int 149(1):35-38

9. Renner SM, Tsitsopoulos PP, Dimitriadis AT, Voronov LI, Havey RM, Carandang G, McIntosh B, Carson C, Ty D, Ringelstein JG, Patwardhan AG (2011) Restoration of spinal alignment and disk mechanics following polyetheretherketone wafer kyphoplasty with StaXx FX. AJNR Am J Neuroradiol 32(7):1295-1300

10. Boger A, Heini P, Windolf M, Schneider E (2007) Adjacent vertebral failure after vertebroplasty: a biomechanical study of low-modulus PMMA cement. Eur Spine J 16(12):2118-2125

11. Boger A, Wheeler KD, Schenk B, Heini PF (2009) Clinical investigations of polymethylmethacrylate cement viscosity during vertebroplasty and related in vitro measurements. Eur Spine J 18(9):1272-1278

12. Heini PF, Berlemann U (2001) Bone substitutes in vertebroplasty. Eur Spine J 10:S205-S213 Suppl 2

13. Heini PF, Berlemann U, Kaufmann M, Lippuner K, Fankhauser C, van Landuyt P (2001) Augmentation of mechanical properties in osteoporotic vertebral bones-a biomechanical investigation of vertebroplasty efficacy with different bone cements. Eur Spine J 10(2):164-171

14. Orler R, Frauchiger LH, Lange U, Heini PF (2006) Lordoplasty: report on early results with a new technique for the treatment of vertebral compression fractures to restore the lordosis. Eur Spine J 15(12): 1769-1775

15. Flors L, Lonjedo E, Leiva-Salinas C, Marti-Bonmati L, MartinezRodrigo JJ, Lopez-Perez E, Figueres G, Raoli I (2009) Vesselplasty: a new technical approach to treat symptomatic vertebral compression fractures. Am J Roentgenol 193(1):218-226

16. Rotter R, Martin H, Fuerderer S, Gabl M, Roeder C, Heini P, Mittlmeier T (2010) Vertebral body stenting: a new method for vertebral augmentation versus kyphoplasty. Eur Spine J 19(6):916-923
17. Kerr SM, Liechty B, Patel R, Harrop JS (2008) Percutaneous vertebral compression fracture management with polyethylene mesh-contained morcelized allograft bone. Curr Rev Musculoskelet Med 1(2):84-87

18. Liu JB, Tang XM, Xu NW, Bao HT (2008) Preliminary results for the treatment of a pain-causing osteoporotic vertebral compression fracture with a sky bone expander. K J Radiol $9(5): 420-425$

19. Olan W (2009) Structural kyphoplasty: a novel approach that is safe and effective for vertebral fracture repair with early results suggesting a lower subsequent fracture rate. J Neuro Interv Surg 1(1):77

20. Buchbinder R, Osborne RH, Ebeling PR, Wark JD, Mitchell P, Wriedt C, Graves S, Staples MP, Murphy B (2009) A randomized trial of vertebroplasty for painful osteoporotic vertebral fractures. N Engl J Med 361(6):557-568

21. Kallmes DF, Comstock BA, Heagerty PJ, Turner JA, Wilson DJ, Diamond TH, Edwards R, Gray LA, Stout L, Owen S, Hollingworth W, Ghdoke B, Annesley-Williams DJ, Ralston SH, Jarvik JG (2009) A randomized trial of vertebroplasty for osteoporotic spinal fractures. N Engl J Med 361(6):569-579

22. Fisher CG, Vaccaro AR (2010) The highest level of evidence in a high impact journal: is this the final verdict? Spine 35(15):E676E677

23. Fisher CG, Vaccaro AR, Whang PG, Prasad SK, Angevine PD, Mulpuri K, Thomas KC, Patel AA (2011) Evidence-based recommendations for spine surgery. Spine 36(14):E897-E903

24. Noonan P (2009) Randomized vertebroplasty trials: bad news or sham news? Am J Neuroradiol 30(10):1808-1809

25. Yi L, Jingping B, Gele J, Baoleri X, Taixiang W (2006) Operative versus non-operative treatment for thoracolumbar burst fractures without neurological deficit. Cochrane Database Syst Rev (4):CD005079

26. Rousing R, Hansen KL, Andersen MO, Jespersen SM, Thomsen K, Lauritsen JM (2010) Twelve-months follow-up in forty-nine patients with acute/semiacute osteoporotic vertebral fractures treated conservatively or with percutaneous vertebroplasty: a clinical randomized study. Spine 35(5):478-482

27. Wardlaw D, Cummings SR, Van Meirhaeghe J, Bastian L, Tillman JB, Ranstam J, Eastell R, Shabe P, Talmadge K, Boonen S (2009) Efficacy and safety of balloon kyphoplasty compared with non-surgical care for vertebral compression fracture (FREE): a randomised controlled trial. Lancet 373(9668):1016-1024

28. Kallmes DF, Jarvik JG (2009) Spinal augmentation research: FREE at last? Lancet 373(9668):982-984

29. Longo UG, Denaro V (2009) Spinal augmentation: what have we learnt? Lancet 373(9679):1947 (author reply 1947-1948)

30. Klazen CA, Lohle PN, de Vries J, Jansen FH, Tielbeek AV, Blonk MC, Venmans A, van Rooij WJ, Schoemaker MC, Juttmann JR, Lo TH, Verhaar HJ, van der Graaf Y, van Everdingen KJ, Muller AF, Elgersma OE, Halkema DR, Fransen H, Janssens X, Buskens E, Mali WP (2010) Vertebroplasty versus conservative treatment in acute osteoporotic vertebral compression fractures (Vertos II): an open-label randomised trial. Lancet 376(9746):1085-1092 